\title{
BMJ Open Preschoolers' parent-rated health disparities are strongly associated with measures of adiposity in the Lifeways cohort study children
}

\author{
Aakash Shrivastava, Celine Murrin, Cecily C Kelleher
}

To cite: Shrivastava A,

Murrin C, Kelleher CC.

Preschoolers' parent-rated health disparities are strongly associated with measures of adiposity in the Lifeways cohort study children. BMJ Open 2014;4:e005328. doi:10.1136/bmjopen-2014005328

- Prepublication history and additional material is available. To view please visit the journal (http://dx.doi.org/ 10.1136/bmjopen-2014005328).

Received 23 March 2014 Revised 26 June 2014 Accepted 27 June 2014

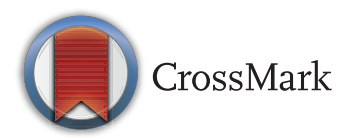

School of Public Health, Physiotherapy and Population Science, University College Dublin, Dublin 4, Republic of Ireland

Correspondence to Professor Cecily C Kelleher; cecily.kelleher@ucd.ie

\section{ABSTRACT}

Objective: To examine the relationship between lifecourse factors from preschoolers' microecosystem and their parent-reported (mother-reported) health (PRH), following them prospectively from preconception to age 5 years. To investigate if preschoolers' body mass index (BMI) and waist circumference were associated with preschoolers' PRH when controlled for lifecourse predictors.

Design: Lifeways cross-generation cohort study.

Setting: Ireland.

Participants: of 1082 families, $62 \%$ mothers responded on a health and lifestyle questionnaire at follow-up. Food frequency, BMI and waist circumference were measured. There were 547 family data sets available for analysis of children's PRH.

Main outcome measure: Mother-reported children's PRH at age 5. Associations with child's individual and familial exposures from preconception to age 5 years examined using logistic regression.

Results: In univariate analysis, relatively positive rating of children's PRH were associated with children's lower intake of fats (OR $(95 \% \mathrm{Cl}) 2.2(1.1$ to 4.3)), higher intake of fruits/vegetables (OR $(95 \% \mathrm{Cl})$ 2.2 (1.1 to 4.3)); as well as familial socioeconomic characteristics \{higher household income $(\mathrm{OR}(95 \% \mathrm{Cl})$ 3.0 (1.6 to 5.9)), non-entitlement to means-tested healthcare (OR ( $95 \% \mathrm{Cl}) 2.1$ (1.0 to 4.3)), mothers' higher education (OR $(95 \% \mathrm{Cl}) 1.9(1.0$ to 3.6$))\}$, psychosocial characteristics (father's participation in study (OR $(95 \% \mathrm{Cl}) 2.1$ (1.0 to 4.3)), mothers' perceiving better support from partner $(\mathrm{OR}(95 \% \mathrm{Cl})$ $2.3(1.2$ to 4.3$))$, children $(\mathrm{OR}(95 \% \mathrm{Cl}) 1.9$ (1.0 to 3.7)) or relatives $(\mathrm{OR}(95 \% \mathrm{Cl}) 2.2(1.1$ to 4.1$))\}$, parents' lifestyle \{mothers' lower intake of energy (OR $(95 \% \mathrm{Cl}) 2.2$ (1.1 to 4.3)), fathers' non-smoking status (OR (95\% Cl) 2.2 (1.1 to 4.4))\} and parents' health \{mothers' self-rated health relatively positive (OR $(95 \%$ CI) 5.1 (2.6 to 9.9)), fathers' self-rated health relatively positive (OR (95\% Cl) 3.0 (1.5 to 6.0))\}.

In multivariable analysis $\left(\chi^{2}=34.2, \mathrm{df}=21, \mathrm{~N}=303\right.$, $\left.R^{2}=0.26, p<0.05\right)$, one of the two strong predictors of children's relatively positive PRH was child not being obese by International Obesity Task Force classification (OR (95\% Cl) 5.5 (1.4 to 21.0)), observed also using BMI $\left(\mathrm{kg} / \mathrm{m}^{2}\right.$; OR $(95 \% \mathrm{Cl}) 0.73(0.58$ to 0.93$\left.)\right)$ or waist circumference (cm; OR (95\% Cl) 0.89 (0.81 to 0.98))

\section{Strengths and limitations of this study}

- Nationally representative sample of preschoolage children.

- Examines the influence of lifecourse adversities, prospectively measured from preconception to age 5 on children's general health at age 5 . The study analyses demographic, anthropometric, lifestyle, food and nutrients intake, psychosocial, socioeconomic and health-related exposures from children's individual as well as parental experiences.

- Demonstrates a significant and independent association between preschoolers' measured $\mathrm{BMI}$ as well as waist circumference and their general health status.

- The study is limited by a relatively small sample and use of parent-reported health status.

as continuous variables. The other significant predictor was mothers' self-rated health relatively positive (OR (95\% Cl) 4.2 (1.5 to 12.2)).

Conclusions: Preschoolers' health is adversely associated with obesity and this is independent of lifecourse and social and environmental inequalities. The findings suggest that reducing childhood obesity and improving maternal health may be useful ways to improve child's global health.

\section{INTRODUCTION}

The development of children is critical to their well-being as adults, ${ }^{1}{ }^{2}$ and across the lifecourse even subjective estimates may be useful to reflect objectively measured health. ${ }^{3}{ }^{4}$ Bronfenbrenner ${ }^{5}$ emphasised the importance of children's microecosystem in their development. Recently, the WHO's Commission on Social Determinants of Health (CSDH) presented a Total Environment Assessment Model for Early Child Development (TEAM-ECD) ${ }^{6}{ }^{6}$ which again illustrates the importance of individual 
and family spheres of influence on children's health. The relevance of socioeconomic, psychosocial and lifestyle environment in child development and health is widely acknowledged. ${ }^{6-8}$

According to the lifecourse hypothesis, risk transmission is characterised by critical periods and accumulation of risk models. ${ }^{9}$ Life Course Health Development (LCHD) framework ${ }^{10}$ suggests that health is a consequence of multiple determinants that change in context of time and circumstances as an individual develops; these experiences are programmed into bio-behavioural regulatory systems during certain critical and sensitive periods of an individual's lifetime to decide their health trajectory. The lifecourse framework on childhood disadvantage and adult health ${ }^{11}$ suggests that parental and childhood circumstances from the point of conception influence an individual's health in later life, and the individual's childhood health and later life circumstances may further add to this foundation. Based on this, Hertzman et $a l^{12}$ examined self-rated health in adulthood using an integrated lifecourse framework. There are a few other studies which have also examined lifecourse determinants of adult global ${ }^{13}{ }^{14}$ or specific health status. ${ }^{15}$ On the contrary, the literature on the determinants of child global health status is sparse, ${ }^{16} 17$ particularly for the preschool-age children. ${ }^{18}$ Even rarer are studies whose examination includes early lifecourse determinants of child global health status.

Thus, the first objective of our analysis was to prospectively examine the relationship between demographic, anthropometric, lifestyle, nutritional, psychosocial, socioeconomic and health-related lifecourse exposures taken from the children's individual and family spheres of influence starting from preconception up to age 5 years and their global health status at preschool age.

In social epidemiology, the construct of 'embodiment' refers to the biological expression of an individual's materio-social world. ${ }^{19}{ }^{20}$ Similarly in lifecourse epidemiology, it is hypothesised that early life experiences get 'biologically embedded' during critical or sensitive periods of child development leading to gradients in health. ${ }^{21} 22$

The Foresight report identifies a large array of environmental determinants of obesity, a number of which are again related to early child development. ${ }^{23}$ This suggests obesity as pivotal risk factor for subsequent health conditions. ${ }^{24}$

The negative relationship between obesity and selfrated health is now increasingly reported in adult populations, ${ }^{25}{ }^{26}$ some indicating a temporal relationship ${ }^{27} 28$ and suggesting that obesity increases health inequalities over time. ${ }^{28}$ However, evidence on the relationship between obesity and health is relatively limited in child population studies and those available have reported health-related-quality-of-life (HR-QoL) ${ }^{29}$ instead of a generic measure such as global self-rated health. Moreover, this association is yet to be established for preschool-age children. To the best of our knowledge, just two population-based studies have examined this association in preschool age-group children ${ }^{30} 31$ and neither had nutritional information.

In the Longitudinal Study of Australian Children, Wake et $a l^{30}$ did not find a significant difference in global health status of overweight/obese and normal weight 4-5-year-old children. Skinner et $a l l^{31}$ using data on 3-5-year-olds from the US National Health and Nutrition Examination Survey, reported a poorer global health status in obese and severely obese preschoolers. Neither of these studies accounted for a number of possibly relevant confounders, including parental body mass index (BMI), parental health and nutritional variables.

We thus hypothesised that similar to findings from studies on older age groups, anthropometric markers of child obesity in our preschool-age children study would also demonstrate a negative association with their global health status. The next objective of our analysis was to examine whether anthropometric markers of child obesity would emerge as strong predictors of global health status when accounted for other socioeconomic, psychosocial and lifestyle environmental factors in a multivariable model.

\section{METHODS}

The Lifeways cross-generation cohort study comprises three generations of 1082 Irish families and was established in 2001-2003; the recruitment procedure of this nationally representative cohort has been described previously. ${ }^{32-34}$ The a priori purpose was to examine familial and cross-generation influences on early childhood development over the first 5 years of children's lives. Briefly, would-be mothers were at random recruited from the two regional maternity hospitals in the Republic of Ireland to get a representative sample. A comparison between the Lifeways mothers and a nationally representative sample of women of the same age group from the SLÁN (Survey of Lifestyle, Attitudes and Nutrition) surveys of Republic of Ireland ${ }^{35}$ confirmed that the Lifeways mothers were satisfactorily representative of the Irish general women on sociodemographic characteristics. ${ }^{33}$

At this early pregnancy stage, mothers completed a health and lifestyle status questionnaire adapted from a validated instrument developed for Irish national SLÁN surveys. ${ }^{35}$ Mothers reported their pre-pregnancy height $(\mathrm{cm})$ and weight $(\mathrm{kg})$ and their smoking status during pregnancy. Mothers' and partners' socioeconomic status was recorded. Subsequently at birth, the live infants were added to the cohort along with maternity and birthrelated hospital information.

In 2007-2008, when these children averaged 5 years of age, the cohort follow-up recorded a $62 \%$ response rate. $^{34} 36$ Though mothers who responded to the follow-up were more likely to be of higher socioeconomic status, these mothers did not significantly differ in their baseline anthropometric characteristics 
(including BMI) from non-responders. ${ }^{34} 36$ At this 5-year follow-up, mothers repeated the health and lifestyle assessment questionnaire, with additional questions related to her family, including a five-level Likert item question "In general, would you say your/your partner's/your Lifeways child's current health is Excellent, Very Good, Good, Fair or Poor." Mothers provided information on family's socioeconomic, psychosocial and lifestyle status. Mothers reported their habitual dietary intake for the previous year on a semiquantitative food frequency (SQFFQ) instrument developed from the EPIC study (European Prospective Investigation into Cancer and Nutrition) and validated for Irish adult population. ${ }^{37}$ Mothers also gave details for the Lifeways child's habitual diet for the previous year using a different SQFFQ instrument adapted from the UK National Diet and Nutrition Survey of 4.5-year-old children. ${ }^{38}$ The mothers' and children's SQFFQ was validated in the Lifeways study using a 7-day weighed food diary in a subsample. ${ }^{36}$ Food items were aggregated by defined shelves (food groups) of the Irish food pyramid, and assessment was made for average servings per day of standard food item portions consumed from the 'top' and 'fruit and vegetable' food groups (shelves of Irish food pyramid). The 'top' food group comprises of high-calorie fat and sugar-rich foods. Total energy (kcal) and total fats $(\mathrm{g})$ intake was computed using conversion values from McCance and Widdowson's food composition tables ${ }^{39}$ with a specially developed FFQ software V.1.0. ${ }^{40}$

Mothers and children, and if available fathers, were offered at 5-year follow-up an anthropometric assessment at their home for height $(\mathrm{cm})$, weight $(\mathrm{kg})$ and waist circumference $(\mathrm{WC} ; \mathrm{cm})$ using a standardised protocol, ${ }^{34}{ }^{36}$ with $80-85 \%$ mothers and children participating. BMI was calculated from weight and height information $\left(\mathrm{kg} / \mathrm{m}^{2}\right)$.

Thus, variables from discrete stages (pre-pregnancy, early pregnancy, at birth, early infancy and 5-year follow-up) of child's early development representing lifecourse exposures from distinct domains (demographic, anthropometric, socioeconomic, psychosocial, lifestyle, nutritional and health) of child's individual and family spheres of influence ${ }^{6-8}$ were considered to analyse determinants of child's health status at age 5. The selection of variables, domains and spheres of influence are based on the CSDH constructed TEAM-ECD, a model of early child development. ${ }^{6-8}$ These lifecourse variables have been summarised as per time frame in table 1 . This lifecourse time frame highlights the stages and transition points relevant from perspective of child's health development. ${ }^{10}$ Additional details on these variables are provided in etable 1 available in the web-only supplement. The independent variables have been arranged as childrelated, family-related, mother-related, father-related groups for ease of presentation.

Children's global health status rated in proxy by their mothers, hereafter referred to as parent-rated health (PRH), was the outcome variable of interest. The 5-graded scale response was dichotomised as relatively positive health (excellent or very good) and relatively negative health (poor or fair or good), based on similar dichotomisation in other studies on preschool and school children. ${ }^{17} 18{ }^{30}$ It is reasonable to take a higher cut-off when dichotomising this age dependent variable in this very young age group as there would be very limited numbers of poor or fair health children. ${ }^{17} 1841$

Initially, univariate associations were established between the independent predictors and children's PRH using independent Student $\mathrm{t}$ tests or $\chi^{2}$ tests. Independent categorical variables were dichotomised in a manner that allowed contrasting extreme levels against the others. Thus, using International Obesity Task Force (IOTF) cut-offs, children's BMI was dichotomised as obese versus overweight or normal weight. Similarly, nutrition variables ordered in quintiles were dichotomised as the extreme quintile (1st or 5th) versus the rest.

Table 1 Independent variables examined from lifecourse of 5-year-old children

\begin{tabular}{ll}
\hline Lifecourse & Independent variables \\
\hline Pre-pregnancy & Maternal pre-pregnancy BMI \\
Early pregnancy & Family stability \\
& Maternal smoking in pregnancy, maternal education level \\
& Paternal education level \\
Birth & Child's birth weight, gestational age, gender \\
& Maternal parity \\
Infancy & Child's breastfeeding status \\
When children & Child's age, height, BMI, waist circumference, food intake: top and fruits and vegetables food \\
averaged 5 years age & groups, nutrient intake: energy and fats intake \\
& $\begin{array}{l}\text { Family household weekly income, entitlement to means tested healthcare benefits scheme, family } \\
\text { structure (marital status), support from partner, parents, children and relatives }\end{array}$ \\
& Maternal age, height, BMI, waist circumference, smoking, employment status, food intake: top and \\
& fruits and vegetables food groups, nutrient intake: energy and fats intake, self-rated health status \\
& Paternal height, BMI, waist circumference, smoking, employment status, self-rated health status
\end{tabular}

BMI, body mass index. 
From these independent variables, principally chosen on the basis of their relevance to the child's development ${ }^{6-8}$ all those that qualified at significance level $20 \%$ $(\mathrm{p}<0.2)^{42}$ in univariate analyses were force entered into a multivariable logistic regression model. BMI $\left(\mathrm{kg} / \mathrm{m}^{2}\right)$ and WC $(\mathrm{cm})$, the anthropometric markers of obesity, were tested separately in independent multivariable models. They were not analysed together within a model as results of possible interactions among body composition variables would have been difficult to interpret. ${ }^{43} 44$ Initially, BMI was tested as a categorical variable in a model, followed by two additional models substituting it with BMI and then WC as continuous variables. Other independent variables were tested as categorical variables. Written informed consent was obtained from study participants.

\section{RESULTS}

There were 547 family data sets available for analysis of children's PRH. Table 2 presents the univariate associations between children's lifecourse variables and PRH. Within the individual spheres of influences, children's lifestyle behaviours (lower intake of fatty/sugary foods and total fats, and higher intake of fruits/vegetables) and their anthropometric measures at age 5 (not being obese, lower BMI and lower WC) are qualified as determinants of children's relatively positive PRH for further examination in the multivariable model.

In other words, retaining $\mathrm{p}<0.2$ as the criterion for significance, the children's healthy food and nutrient intake habits-such as lower intake of unhealthy fat-rich and sugar-rich foods (servings/day; OR (95\% CI) 1.7 $(0.8$ to 3.4$))$ or total fats $(\mathrm{g})$ in their meals (OR $(95 \%$ CI) 2.2 (1.1 to 4.3)) and higher intake of healthy fruits and vegetables (servings/day; OR (95\% CI) 2.2 (1.1 to 4.3)) - were positively associated with their favourable rating for health by their mothers. Conversely, children's higher BMI $\left(\mathrm{kg} / \mathrm{m}^{2}\right.$; OR $(95 \% \mathrm{CI}) 0.85$ (0.71 to 1.03$)$ ) and WC $(\mathrm{cm}$; OR $(95 \% \mathrm{CI}) 0.95$ (0.88 to 1.02$))$ were inversely associated with a positive parental-rated health status.

Within the family sphere of influences, socioeconomic status (higher household income, non-entitlement to subsidised healthcare, both parents' higher education status and father's employment status), psychosocial status (father's study participation, mother's perceived social support), mother's lifestyle behaviours (lower intake of fatty/sugary foods, total energy and total fats), father's lifestyle behaviours (non-smoker) and both parents' health status (relatively positive self-rated health) are qualified as determinants of children's relatively positive PRH for further examination in the multivariable model.

In other words, by maintaining $\mathrm{p}<0.2$ as the criterion for significance, several indicators of a family's better socioeconomic status-such as higher household income (Euros/week; OR (95\% CI) 3.0 (1.6 to 5.9)), not requiring subsidised healthcare (OR (95\% CI) 2.1 (1.0 to 4.3)), mother having a third-level education (OR (95\% CI) 1.9 (1.0 to 3.6)), father having a third-level education (OR (95\% CI) 1.9 (1.0 to 3.6)), father being self-employed (OR (95\% CI) 2.5 (0.8 to 7.9)); family's better psychosocial status-such as father's involvement in family affairs (OR (95\% CI) 2.1 (1.0 to 4.3)), mothers perceiving a positive social support from spouse (OR (95\% CI) 2.3 (1.2 to 4.3)), parents (OR (95\% CI) 2.0 (1.0 to 4.1$)$ ), children (OR (95\% CI) 1.9 (1.0 to 3.7$)$ ) or relatives (OR (95\% CI) 2.2 (1.1 to 4.1)); family's better lifestyle and food and nutrient intake habits-such as mother's lower intake of unhealthy fat-rich and sugarrich foods (servings/day; OR (95\% CI) 1.7 (0.8 to 3.4)), total energy (kcal; OR (95\% CI) $2.2(1.1$ to 4.3$)$ ) and total fats (g; OR (95\% CI) 1.7 (0.8 to 3.4)) in her meals, fathers not being a smoker (OR (95\% CI) 2.2 (1.1 to 4.4)); and family's better health status-such as mother (OR (95\% CI) 5.1 (2.6 to 9.9)) and father (OR (95\% CI) 3.0 (1.5 to 6.0) ) having a positively rated health status were positively associated with children's favourable rating for health by their mothers.

Table 3 presents the multivariable model for association between qualifying lifecourse variables and children's relatively positive PRH at age 5. A significantly strong predictor of children's relatively positive PRH was child's not being obese by IOTF classification (OR (95\% CI) 5.5 (1.4 to 21.0)). When BMI was tested as a continuous variable, there was 0.73 (95\% CI 0.58 to 0.93 ) times lower odds of the child being positively rated on health status for every $1 \mathrm{~kg} / \mathrm{m}^{2}$ increase in their BMI. Similarly, in the WC model, for every $1 \mathrm{~cm}$ increase there was 0.89 (95\% CI 0.81 to 0.98 ) times lower odds of the child getting a relatively positive rating on health status. Thus, the association between children's BMI or WC and their PRH only strengthened following adjustments in this multivariate model, irrespective of being analysed as a categorical or continuous variable. Another significant predictor of children's relatively positive PRH was mother's having rated her own health as relatively positive. These predictors maintained the highest strength of association with children's health status when independent variables were standardised (not reported here). None of the other variables reached the level of statistical significance. The models explained over $25 \%$ of variance for children's PRH.

\section{DISCUSSION}

This analysis showed that determinants from both child's individual and family spheres have an influence on child's health at preschool age. The factors from all three material, psychosocial and lifestyle domains, the major explanations for child health inequalities, ${ }^{8}$ were associated at univariate levels. However, in the final model, this analysis clearly demonstrated a negative association between child's obesity and health status. Child's not being obese was one of the significantly strong 
Table 2 Univariate lifecourse associates of children's relatively positive PRH ( $N=547)$

\begin{tabular}{|c|c|c|c|c|c|c|c|}
\hline & \multirow[b]{2}{*}{$\mathbf{N}$} & \multicolumn{2}{|c|}{$\begin{array}{l}\text { Relatively negative PRH } \\
(n=42)\end{array}$} & \multicolumn{2}{|c|}{$\begin{array}{l}\text { Relatively positive PRH } \\
(\mathrm{n}=505)\end{array}$} & \multirow[b]{2}{*}{ OR } & \multirow[b]{2}{*}{$95 \% \mathrm{Cl}$} \\
\hline & & Per cent (n) & Mean (SD) & Per cent (n) & Mean (SD) & & \\
\hline \multicolumn{8}{|l|}{ Child's individual characteristics } \\
\hline $\begin{array}{l}\text { Birth weight adjusted for gestational } \\
\text { age }(\mathrm{g})\end{array}$ & 487 & (34) & $3564.1(616)$ & $(453)$ & $3548.4(552)$ & 1.00 & (0.999 to 1.001$)$ \\
\hline Child's age (years) & 547 & (42) & $5.42(0.23)$ & $(505)$ & $5.46(0.25)$ & & \\
\hline Gender & 547 & & & & & & \\
\hline Male & & $8.0(22)$ & & $92.0(242)$ & & Ref & \\
\hline Female & & $7.1(21)$ & & $92.9(262)$ & & 1.14 & (0.60 to 2.20$)$ \\
\hline BMI $\left(\mathrm{kg} / \mathrm{m}^{2}\right)$ & 464 & (35) & $17.09(2.5)$ & (429) & $16.59(1.6)$ & 0.85 & $(0.71 \text { to } 1.03)^{\wedge}$ \\
\hline BMI (IOTF) & 464 & & & & & & \\
\hline Obese & & $16.7(5)$ & & $83.3(25)$ & & Ref & \\
\hline Overweight/normal & & $6.9(30)$ & & 93.1 (404) & & 2.69 & $(0.96 \text { to } 7.54)^{\wedge}$ \\
\hline Waist circumference $(\mathrm{cm})$ & 462 & (35) & $57.01(6.8)$ & (427) & $55.88(4.3)$ & 0.95 & $(0.88$ to 1.02$) \dagger$ \\
\hline Height $(\mathrm{cm})$ & 464 & (35) & $111.6(5.6)$ & (429) & $112.1(4.8)$ & 1.02 & $(0.95$ to 1.10$)$ \\
\hline Breast feeding & 528 & & & & & & \\
\hline Not breast fed & & $6.5(16)$ & & $93.5(229)$ & & Ref & \\
\hline Breast fed & & $8.8(25)$ & & $91.2(258)$ & & 0.72 & $(0.38$ to 1.38$)$ \\
\hline Energy (kcal) & 547 & & & & & & \\
\hline Quintile 5 (>1794) & & $10(11)$ & & $90.0(99)$ & & Ref & \\
\hline Quintile 1-4 & & 7.1 (31) & & $92.9(406)$ & & 1.46 & $(0.71$ to 3.00$)$ \\
\hline Fats $(\mathrm{g})$ & 547 & & & & & & \\
\hline Quintile 5 (>62.9) & & $12.8(14)$ & & $87.2(95)$ & & Ref & \\
\hline Quintile 1-4 & & $6.4(28)$ & & $93.6(410)$ & & 2.16 & $(1.09 \text { to } 4.26)^{*}$ \\
\hline Top food group (servings/day) & 547 & & & & & & \\
\hline Quintile 5 (>6.47) & & $10.9(12)$ & & $89.1(98)$ & & Ref & \\
\hline Quintile 1-4 & & $6.9(30)$ & & $93.1(407)$ & & 1.66 & $(0.82$ to 3.36$) \dagger$ \\
\hline Fruits veg food group (servings/day) & 547 & & & & & & \\
\hline Quintile $1(<2.1)$ & & $12.8(14)$ & & $87.2(95)$ & & Ref & \\
\hline Quintile 2-5 & & $6.4(28)$ & & $93.6(410)$ & & 2.16 & $(1.09 \text { to } 4.26)^{*}$ \\
\hline \multicolumn{8}{|l|}{ Family Characteristics } \\
\hline Household weekly income & 509 & & & & & & \\
\hline Less than $€ 760$ & & $13.3(26)$ & & $86.7(170)$ & & Ref & \\
\hline More than $€ 760$ & & $4.8(15)$ & & $95.2(298)$ & & 3.04 & $(1.57 \text { to } 5.90)^{\star \star}$ \\
\hline Entitlement to general medical card & 532 & & & & & & \\
\hline Entitled & & $13(12)$ & & $87.0(80)$ & & Ref & \\
\hline Not entitled & & $6.6(29)$ & & $93.4(411)$ & & 2.13 & $(1.04 \text { to } 4.34)^{*}$ \\
\hline Fathers' participation & 547 & & & & & & \\
\hline No & & $9.7(31)$ & & $90.3(290)$ & & Ref & \\
\hline Yes & & $4.9(11)$ & & $95.1(215)$ & & 2.09 & $(1.03 \text { to } 4.25)^{*}$ \\
\hline Marital status & 542 & & & & & & \\
\hline Others & & $11.4(5)$ & & $88.6(39)$ & & Ref & \\
\hline Married/cohabiting & & $7.2(36)$ & & $92.8(462)$ & & 1.65 & (0.61 to 4.43 ) \\
\hline Elder children in family (parity) & 535 & & & & & & \\
\hline Nullipara & & $8(18)$ & & $92.0(207)$ & & Ref & \\
\hline Multipara & & $7.7(24)$ & & $92.3(286)$ & & 1.04 & (0.55 to 1.96$)$ \\
\hline Support from spouse/partner & 538 & & & & & & \\
\hline Lesser support & & $12.9(17)$ & & $87.1(115)$ & & Ref & \\
\hline More support & & $6.2(25)$ & & $93.8(381)$ & & 2.25 & $(1.18 \text { to } 4.32)^{*}$ \\
\hline Support from parents & 487 & & & & & & \\
\hline Lesser support & & $12.5(12)$ & & $87.5(84)$ & & Ref & \\
\hline More support & & $6.6(26)$ & & 93.4 (365) & & 2.01 & $(0.97 \text { to } 4.14)^{\wedge}$ \\
\hline Support from children & 532 & & & & & & \\
\hline Lesser support & & $10.6(20)$ & & 89.4 (169) & & Ref & \\
\hline More support & & $5.8(20)$ & & 94.2 (323) & & 1.91 & $(1.00 \text { to } 3.65)^{\star}$ \\
\hline Support from close relatives & 510 & & & & & & \\
\hline Lesser support & & $12.4(19)$ & & $87.6(134)$ & & Ref & \\
\hline More support & & $6.2(22)$ & & $93.8(335)$ & & 2.16 & $(1.13 \text { to } 4.12)^{*}$ \\
\hline Maternal characteristics & & & & & & & \\
\hline Pre-pregnancy BMI $\left(\mathrm{kg} / \mathrm{m}^{2}\right)$ & 475 & (36) & $23.3(3.3)$ & (439) & $23.8(3.9)$ & 1.04 & (0.94 to 1.14$)$ \\
\hline
\end{tabular}


Table 2 Continued

\begin{tabular}{|c|c|c|c|c|c|c|c|}
\hline & \multirow[b]{2}{*}{$\mathbf{N}$} & \multicolumn{2}{|c|}{$\begin{array}{l}\text { Relatively negative PRH } \\
(\mathrm{n}=42)\end{array}$} & \multicolumn{2}{|c|}{$\begin{array}{l}\text { Relatively positive PRH } \\
(n=505)\end{array}$} & \multirow[b]{2}{*}{ OR } & \multirow[b]{2}{*}{$95 \% \mathrm{Cl}$} \\
\hline & & Per cent (n) & Mean (SD) & Per cent $(n)$ & Mean (SD) & & \\
\hline \multicolumn{8}{|l|}{ Pre-pregnancy BMI (WHO cut-offs) } \\
\hline Obese & & $2.6(1)$ & & $97.4(38)$ & & Ref & \\
\hline Overweight/normal & & $8(35)$ & & $92.0(401)$ & & 0.30 & (0.04 to 2.26$)$ \\
\hline Mother's age (years) & 546 & (42) & $36.5(6.3)$ & (504) & $37.1(5.3)$ & 1.02 & (0.96 to 1.08$)$ \\
\hline $\mathrm{BMI}$ at 5-year follow-up $\left(\mathrm{kg} / \mathrm{m}^{2}\right)$ & 432 & & $25.6(3.9)$ & & $26.3(5.0)$ & 1.03 & (0.95 to 1.12$)$ \\
\hline $\begin{array}{l}\text { BMI at 5-year follow-up (WHO } \\
\text { cut-offs) }\end{array}$ & & \\
\hline Obese & & $7.2(5)$ & & $92.8(64)$ & & Ref & \\
\hline Overweight/normal & & $7.4(27)$ & & $92.6(336)$ & & 0.97 & (0.36 to 2.62$)$ \\
\hline Waist circumference (cm) & 434 & (31) & $85.3(10.6)$ & (403) & $87.6(11.9)$ & 1.02 & (0.99 to 1.05$)$ \\
\hline Height $(\mathrm{cm})$ & 454 & (33) & $161.9(6.8)$ & (421) & $162.9(6.0)$ & 1.03 & (0.97 to 1.09$)$ \\
\hline Smoking in pregnancy & 534 & & & & & & \\
\hline Smoker & & $8.1(8)$ & & $91.9(91)$ & & Ref & \\
\hline Non-smoker & & $7.6(33)$ & & 92.4 (402) & & 1.07 & (0.48 to 2.4$)$ \\
\hline Smoking at 5-year follow-up & 541 & & & & & & \\
\hline Smoker & & $7.6(9)$ & & $92.4(110)$ & & Ref & \\
\hline Non-smoker & & $7.6(32)$ & & $92.4(390)$ & & 1.0 & (0.46 to 2.15$)$ \\
\hline Energy (kcal) & 546 & & & & & & \\
\hline Quintile 5 (>2570.9) & & $13(14)$ & & $87.0(94)$ & & Ref & \\
\hline Quintile 1-4 & & $6.4(28)$ & & $93.6(410)$ & & 2.18 & $(1.11 \text { to } 4.30)^{*}$ \\
\hline Fats $(\mathrm{g})$ & 546 & & & & & & \\
\hline Quintile 5 (>106) & & $11(12)$ & & $89.0(97)$ & & Ref & \\
\hline Quintile 1-4 & & $6.9(30)$ & & $93.1(407)$ & & 1.68 & $(0.83$ to 3.40$) \dagger$ \\
\hline Top food group (servings/day) & 545 & & & & & & \\
\hline Quintile 5 (>8.35) & & $11(12)$ & & $89.0(97)$ & & Ref & \\
\hline Quintile $1-4$ & & $6.9(30)$ & & $93.1(406)$ & & 1.67 & $(0.83$ to 3.39$) \dagger$ \\
\hline Fruits veg food group (servings/day) & 546 & & & & & & \\
\hline Quintile $1(<4.5)$ & & $9.1(10)$ & & $90.9(100)$ & & Ref & \\
\hline Quintile 2-5 & & $7.3(32)$ & & $92.7(404)$ & & 1.26 & (0.60 to 2.65$)$ \\
\hline Education level & 534 & & & & & & \\
\hline Lower & & $10.4(25)$ & & $89.6(215)$ & & Ref & \\
\hline Third level & & $5.8(17)$ & & $94.2(277)$ & & 1.90 & $(1.00 \text { to } 3.60)^{\star}$ \\
\hline Employment & 545 & & & & & & \\
\hline Not earning & & $6.4(15)$ & & $93.6(221)$ & & Ref & \\
\hline Employed & & $9(22)$ & & $91.0(222)$ & & 0.69 & $(0.35$ to 1.36$)$ \\
\hline Self-employed & & $7.7(5)$ & & $92.3(60)$ & & 0.81 & (0.29 to 2.33 ) \\
\hline Self-reported health & 546 & & & & & & \\
\hline Relatively negative & & $17.1(27)$ & & $82.9(131)$ & & Ref & \\
\hline Relatively positive & & $3.9(15)$ & & 96.1 (373) & & 5.10 & $(2.64 \text { to } 9.93)^{\star \star}$ \\
\hline \multicolumn{8}{|l|}{ Paternal characteristics } \\
\hline BMI at 5-year follow-up $\left(\mathrm{kg} / \mathrm{m}^{2}\right)$ & 66 & (4) & $28.4(5.5)$ & (62) & $27.9(4.1)$ & 0.97 & (0.76 to 1.23$)$ \\
\hline Waist circumference $(\mathrm{cm})$ & 65 & (3) & $94.9(7.6)$ & (62) & $95.9(1.3)$ & 1.01 & $(0.90$ to 1.13$)$ \\
\hline Height $(\mathrm{cm})$ & 66 & (4) & $175.2(2.0)$ & (62) & $175.5(8.0)$ & 1.01 & (0.88 to 1.15$)$ \\
\hline Smoking at 5-year follow-up & 521 & & & & & & \\
\hline Smoker & & $11.5(16)$ & & $88.5(123)$ & & Ref & \\
\hline Non-smoker & & $5.5(21)$ & & 94.5 (361) & & 2.24 & $(1.13 \text { to } 4.42)^{*}$ \\
\hline Education level & 514 & & & & & & \\
\hline Lower & & $11.1(16)$ & & $88.9(128)$ & & Ref & \\
\hline Third level & & $6.2(23)$ & & $93.8(347)$ & & 1.89 & $(0.97 \text { to } 3.68)^{\wedge}$ \\
\hline Employment & 518 & & & & & & \\
\hline Not earning & & $9.2(8)$ & & $90.8(79)$ & & Ref & \\
\hline Employed & & $7.9(24)$ & & $92.1(279)$ & & 1.18 & (0.51 to 2.72$)$ \\
\hline Self-employed & & $3.9(5)$ & & 96.1 (123) & & 2.49 & $(0.79$ to 7.89$) \dagger$ \\
\hline Self-reported health & 510 & & & & & & \\
\hline Relatively negative & & $12.6(20)$ & & 87.4 (139) & & Ref & \\
\hline Relatively positive & & $4.6(16)$ & & 95.4 (335) & & 3.01 & $(1.52 \text { to } 5.99)^{\star *}$ \\
\hline
\end{tabular}

${ }^{*} p<0.05,{ }^{* *} p<0.01, \wedge p<0.1,+p<0.2$.

BMI, body mass index; IOTF, International Obesity Task Force; Ref, reference category (OR=1); PRH, parent-rated health. 
Table 3 Multivariable logistic regression model for predictors of children's relatively positive PRH (N=303)

\begin{tabular}{|c|c|c|c|c|c|c|}
\hline & \multirow{2}{*}{\multicolumn{2}{|c|}{$\begin{array}{l}\text { Relatively } \\
\text { positive PRH } \\
\text { BMI categoricalๆ }\end{array}$}} & \multirow{2}{*}{\multicolumn{2}{|c|}{$\begin{array}{l}\text { Relatively } \\
\text { positive PRH } \\
\text { BMI continuous }\end{array}$}} & \multirow{2}{*}{\multicolumn{2}{|c|}{$\begin{array}{l}\text { Relatively } \\
\text { positive PRH } \\
\text { WC continuous }\end{array}$}} \\
\hline & & & & & & \\
\hline & OR & $95 \% \mathrm{Cl}$ & OR & $95 \% \mathrm{Cl}$ & OR & $95 \% \mathrm{Cl}$ \\
\hline \multicolumn{7}{|l|}{ Child's individual characteristics } \\
\hline BMI (IOTF), obese† vs overweight/normal & 5.48 & $(1.43 \text { to } 21.03)^{*}$ & & & & \\
\hline BMI, $\mathrm{kg} / \mathrm{m}^{2}$ (continuous) & & & 0.73 & $(0.58 \text { to } 0.93)^{\star \star}$ & & \\
\hline WC, $\mathrm{cm}$ (continuous) & & & & & 0.89 & $(0.81 \text { to } 0.98)^{*}$ \\
\hline Fats, g (quintiles), Q5† vs Q1-4 & 1.57 & (0.42 to 5.79$)$ & 1.49 & $(0.40$ to 5.53$)$ & 1.32 & (0.36 to 4.80$)$ \\
\hline $\begin{array}{l}\text { Top food group servings/day (quintiles), Q5† vs } \\
\text { Q1-4 }\end{array}$ & 1.23 & (0.33 to 4.53$)$ & 1.30 & (0.36 to 4.63$)$ & 1.29 & (0.36 to 4.62$)$ \\
\hline $\begin{array}{l}\text { Fruits veg food group servings/day (quintiles), } \\
\text { Q1† vs Q2-5 }\end{array}$ & 2.57 & $(0.75$ to 8.80$)$ & 2.86 & (0.83 to 9.93$)$ & 2.73 & (0.78 to 9.49$)$ \\
\hline \multicolumn{7}{|l|}{ Family characteristics } \\
\hline Household weekly income, less† vs high & 1.85 & (0.63 to 5.40$)$ & 1.76 & $(0.59$ to 5.21$)$ & 1.79 & (0.61 to 5.26$)$ \\
\hline $\begin{array}{l}\text { Entitlement to general medical, card yest } \\
\text { vs no }\end{array}$ & 0.94 & (0.24 to 3.71$)$ & 1.03 & (0.26 to 4.07$)$ & 1.04 & (0.26 to 4.10$)$ \\
\hline Fathers' participation, no† vs yes & 1.88 & (0.68 to 5.21$)$ & 1.86 & $(0.67$ to 5.16$)$ & 2.06 & $(0.74$ to 5.71$)$ \\
\hline Support from spouse/partner, less $†$ vs more & 0.70 & (0.20 to 2.49$)$ & 0.67 & (0.19 to 2.33$)$ & 0.74 & (0.22 to 2.52$)$ \\
\hline Support from parents, lesst vs more & 1.92 & (0.53 to 6.93$)$ & 2.33 & (0.64 to 8.42$)$ & 2.37 & (0.66 to 8.53$)$ \\
\hline Support from children, less $†$ vs more & 1.15 & (0.38 to 3.45$)$ & 1.29 & (0.42 to 3.91$)$ & 1.25 & (0.41 to 3.82$)$ \\
\hline Support from close relatives, less† vs more & 0.86 & (0.23 to 3.13$)$ & 0.84 & (0.24 to 3.02$)$ & 0.84 & (0.23 to 3.01$)$ \\
\hline \multicolumn{7}{|l|}{ Maternal characteristics } \\
\hline Energy, kcal (quintiles), Q5† vs Q1-4 & 1.89 & (0.30 to 11.84$)$ & 2.00 & $(0.31$ to 12.86$)$ & 1.57 & (0.28 to 8.84$)$ \\
\hline Fats, g (quintiles), Q5† vs Q1-4 & 0.72 & (0.09 to 5.54$)$ & 0.59 & (0.07 to 4.77$)$ & 0.92 & (0.13 to 6.41$)$ \\
\hline $\begin{array}{l}\text { Top food group servings/day (quintiles), Q5† vs } \\
\text { Q1-4 }\end{array}$ & 1.08 & (0.29 to 3.94$)$ & 1.30 & (0.36 to 4.65$)$ & 1.18 & (0.32 to 4.34$)$ \\
\hline Education, lowert vs third level & 1.34 & $(0.47$ to 3.78$)$ & 1.35 & $(0.48$ to 3.80$)$ & 1.48 & $(0.53$ to 4.13$)$ \\
\hline $\begin{array}{l}\text { Self-reported health status, Rel.Negative† vs } \\
\text { Rel.Positive }\end{array}$ & 4.20 & $(1.45 \text { to } 12.20)^{\star \star}$ & 4.42 & $(1.53 \text { to } 12.79)^{\star \star}$ & 4.17 & $(1.47 \text { to } 11.87)^{\star *}$ \\
\hline \multicolumn{7}{|l|}{ Paternal characteristics } \\
\hline Current smoking status, yes† vs no & 1.37 & (0.48 to 3.93$)$ & 1.31 & (0.45 to 3.83$)$ & 1.53 & (0.54 to 4.35$)$ \\
\hline Education, lower† vs third level & 0.69 & (0.21 to 2.28$)$ & 0.79 & (0.24 to 2.57$)$ & 0.83 & (0.26 to 2.67$)$ \\
\hline Employment, non-earning † vs self-employed & 1.60 & (0.73 to 3.53$)$ & 1.52 & (0.69 to 3.32$)$ & 1.57 & (0.70 to 3.53$)$ \\
\hline $\begin{array}{l}\text { Self-reported health status, Rel.Negative† vs } \\
\text { Rel.Positive }\end{array}$ & 1.48 & (0.52 to 4.20$)$ & 1.54 & (0.54 to 4.35$)$ & 1.43 & (0.51 to 3.96$)$ \\
\hline $\begin{array}{l}{ }^{*} \mathrm{p}<0.05 \text { (2-tailed), }{ }^{* *} \mathrm{p}<0.01 \text { (2-tailed). } \\
\text { †Reference category }(\mathrm{OR}=1) \text {. } \\
\text { १Child BMI as a categorical variable; model } \chi^{2}=34.2, \mathrm{~d} \\
\text { †Child BMI as a continuous variable; model } \chi^{2}=35.9, \\
\text { §Child WC as a continuous variable; model } \chi^{2}=33.8, d\end{array}$ & r, & $0.034,-2 L L=120$ & mag 2 \& & $\begin{array}{l}\text { erke } R^{2}=0.26 \\
\text { erke } R^{2}=0.27\end{array}$ & & \\
\hline
\end{tabular}

predictors of child's relatively positive health status, which was also observed with measured BMI and WC analysed as continuous variables.

This negative relationship observed between measured obesity and PRH conforms to published literature on primary school age-group children and adolescents. ${ }^{45-47}$ Most importantly, for the first time to our knowledge, this analysis demonstrates the association having adjusted for food and nutrient intake, along with a wide range of other explanatory variables.

Self-rated health is an important and valid measure of morbidity, mortality, longevity and health status, ${ }^{3}{ }^{4}$ also in Irish adult ${ }^{48} 49$ and children. ${ }^{16}$ It is believed to be a more inclusive measure of health than the objective measurements, with a capacity to comprehensively evaluate health dynamics, behaviours and psychophysiological states that are not otherwise easy to measure. ${ }^{3}$ This holistic measure better accommodates the WHO defined concept of health as opposed to a diagnosed specific disease. ${ }^{3}$ Use of parent proxy for child self-reported health is justified for children too young to have adequate cognitive skills. $^{50} 51$ Systematic reviews report good agreement between ratings by children and their parents on child HR-QoL, particularly for physical health domain. ${ }^{50-52}$ Parents tend to be thoughtful when responding to proxy questions and report children's usual health disposition. ${ }^{53}$ Studies on construct validity report positively. ${ }^{54-57}$ Maternal ratings of child's general health status were found sensitive when validated against children's illnesses and other morbidity or healthcare 
indicators, ${ }^{41}{ }^{58-60}$ including evidence of a gradient in strength of these associations. ${ }^{41}$ Many national-level studies have accepted parent proxy as an appropriate measure ${ }^{17} 186162$ and successfully used it to longitudinally demonstrate risk and consequences of child health. ${ }^{1761}$

Self-rated health, a composite measure, represents all domains of HR-QoL, ${ }^{4}$ but better represents physical health than HR-QoL. ${ }^{63}$ Studies on older age-group children have reported stronger/sole negative associations for general/physical health domain of HR-QoL and obesity, ${ }^{46}{ }^{64}$ irrespective whether children themselves or parents reported their HR-QoL, ${ }^{29}$ and also whether BMI was analysed as a categorical $^{45}{ }^{46}$ or continuous variable. ${ }^{6566}$

Another relevance of this analysis is in demonstrating this association of obesity with general health in a nationally representative sample of preschool-age children, for which literature is scant. Though, a few have shown similar association of obesity with specific paediatric conditions or admission history in this age group. $^{30} 31{ }^{67-70}$ A longitudinal study speculated that preschool obesity influences a decline in early-age health, and then both obesity and poor health tracks into adolescence. ${ }^{71}$ The WHO recommends high priority for determinants of health inequalities during early development. ${ }^{72}$

The Lifeways previously demonstrated longitudinal association between parental socioeconomic and lifestyle characteristics and child's BMI and WC. ${ }^{36}$ In this analysis, when same anthropometric measures are included along with material, psychosocial and lifestyle determinants of child obesity and health, a prominent relationship emerges between children's anthropometric measures and health status. One possible explanation is that determinants of health inequalities biologically embed ${ }^{2122}$ in early life and child obesity is an early phenotypic expression of this inequality, though the continued influence of environmental factors is not undermined. Adult ${ }^{25}{ }^{26}$ and adolescence studies ${ }^{46}{ }^{47}$ have also shown this association to be independent of sociodemographic, lifestyle-related or health-related factors.

The observed association between BMI or WC and PRH in the present analysis may be temporal, as demonstrated in adults. ${ }^{27} 28$ Though a number of large-scale cross-sectional studies have shown an association between anthropometric measures of obesity and selfrated health, ${ }^{73}$ only recently a few nationally representative prospective studies have established the temporality of this association in adults. ${ }^{27} 28$ Though this relationship maybe bidirectional to an extent, ${ }^{74} 75$ the mounting evidence from longitudinal birth cohort studies regarding a sequential relationship between lifetime growth trajectories and adult disease, disability and deaths ${ }^{2}$ primarily rules out reverse causality in this association and suggests that the association observed in our birth cohort is also more likely to be temporal. Moreover, the available findings from a few longitudinal studies on primary school age children suggest that at least in the childhood this inverse association found between BMI and HR-QoL is predominantly in the given direction and not the reverse. ${ }^{76} 77$ However, this needs careful interpretation as anthropometric and health data were concurrently collected, and this limitation may be addressed with next sweep of cohort data collection.

This analysis demonstrated that maternal health was strongly predictive of her child's health. One concern is that mother's perception of her own health may bias her perception of her child's health. However, this intergenerational association has been previously reported, ${ }^{41} 5859{ }^{78-81}$ and reporting mothers can effectively discriminate between their own and children's health. ${ }^{41} 5859798082$ Several mechanisms such as inherited susceptibility, uterine environment and shared environment have been suggested for this familial aggregation pattern. ${ }^{58} 7980$

Maternal BMI may be related to both maternal selfrated health and child's BMI, so the observed associations in this analysis could possibly be a reflection of an association between maternal BMI and child's PRH. However, this was not observed in our analysis. Maternal BMI at pre-pregnancy and 5-year follow-up was not associated with child's PRH at univariate level. Also, when maternal BMI was forcibly added into the multivariable model (not reported here), the observed associations did not attenuate.

The study has limitations in use of reported rather than measured health status and a relatively small sample size. Though the study was able to detect the major explanatory domains for child health inequalities documented in the literature, ${ }^{8}$ the relatively small sample size of this study may possibly have underpowered it to detect variables with lesser effect sizes. The complete case approach to analysis reduced the sample size of the final multivariate model, which may have power implications. However, these missing data were on account of an accumulation across a number of variables. On analysis, there was no evidence of selectivity in the participants for whom there were missing data (etable 2). eTable 2, available in the web-only supplement, compares children included and not included in the final model for variables belonging to explanatory domains. It suggests that there were no significant differences in the characteristics of children included and not included (due to missing data) for analysis, suggesting that the children in the final model are representative of the study participants as a whole. It may be argued that the reduced sample size possibly influenced the OR estimate for the association between children's relatively positive PRH and the child's not being obese (using a categorical IOTF classification). Nonetheless, this association between children's anthropometric measures and their PRH variable is likely to be coherent, because these associations remain statistically significant even when BMI and WC are analysed as continuous variables. 
As in most birth cohort studies, ${ }^{83} 84$ the Lifeways birth cohort also experienced the attrition of mothers belonging to lower socioeconomic status in the early stages of the study. Though this may underestimate some socioeconomic inequalities, ${ }^{85}$ it does not negate the exposure-outcome associations detected through regression models of such longitudinal studies. ${ }^{86} 87$

Nevertheless, this study has advantages in use of lifecourse variables from preconception to age of 5 years, with measured BMI and WC data. It also has detailed foods and nutrient data along with other socioeconomic, psychosocial and lifestyle variables for child and both parents.

In conclusion, these analyses from the Lifeways cohort show that lifecourse adversities were associated with mother-reported health for preschoolers, suggesting an early life influence. Preschoolers' BMI and WC demonstrated strong negative associations with mother-reported health independent of socioeconomic, psychosocial, and lifestyle factors, suggesting early biological expression of lifecourse adversities. The findings have important implications in understanding how early life environment may create inequalities in developmental health.

\section{Acknowledgements The authors greatly appreciate the participation of the} Lifeways cohort families.

Contributors The Lifeways Cross-Generation Cohort Study is overseen by an interdisciplinary scientific steering group chaired by CCK, the principal investigator. AS undertook all analyses reported in this manuscript, interpreted the findings and drafted the manuscript. CM contributed to data collection at 5-year follow-up, interpretation of the analysis and critical revision of the manuscript. CCK designed the study, supervised the analyses, interpretation of results and intellectual content of the manuscript. All three authors approved the final version.

Funding The Lifeways Cross-Generation Cohort Study was established as part of European Science Foundation funded 'Social Variations in Health Expectancy in Europe' international research programme and its various sweeps have been funded by the Health Research Board of Ireland.

Competing interests None.

Ethics approval Ethics committees of Coombe University Hospital, Dublin, University College Hospital Galway, University College Dublin, Dublin, and the Irish College of General Practitioners, Ireland.

Provenance and peer review Not commissioned; externally peer reviewed.

Data sharing statement The data manager may be contacted at john. mehegan@ucd.ie for more details on the Lifeways Cross-Generation Cohort Study.

Open Access This is an Open Access article distributed in accordance with the Creative Commons Attribution Non Commercial (CC BY-NC 4.0) license, which permits others to distribute, remix, adapt, build upon this work noncommercially, and license their derivative works on different terms, provided the original work is properly cited and the use is non-commercial. See: http:// creativecommons.org/licenses/by-nc/4.0/

\section{REFERENCES}

1. Barker DJ. Sir Richard Doll Lecture. Developmental origins of chronic disease. Public Health 2012;126:185-9.

2. Power C, Kuh D, Morton S. From developmental origins of adult disease to life course research on adult disease and aging: insights from birth cohort studies. Annu Rev Public Health 2013;34:7-28.
3. Benyamini $Y$. Self-ratings of health and longevity: a health psychologist's viewpoint on epidemiological findings. Eur Health Psychol 2008;10:10-13.

4. Bjorner J, Fayers P, Idler E. Self-rated health. In: Fayers PM, Hays RD, eds. Assessing quality of life in clinical trials: methods and practice. 2nd edn. New York: Oxford University Press, 2005:309-24.

5. Bronfenbrenner U. Ecological models of human development. In: Postlethwaite TNHusen T, eds. International encyclopedia of education. vol 3. 2nd edn. Oxford, England: Elsevier Sciences, Ltd, 1994:1643-7.

6. Siddiqi A, Irwin LG, Hertzman C. Total environment assessment model for early child development. Evidence report for the WHO commission on social determinants of health. World Health Organization, 2007. http://www.who.int/social determinants/ resources/ecd_kn_evidence_report_2007.pdf (accessed 30 Mar 2012).

7. Maggi S, Irwin LJ, Siddiqi A, et al. The social determinants of early child development: an overview. J Paediatr Child Health 2010;46:627-35.

8. Hertzman C, Li J, Mattes E, et al. Social determinants of child health and well-being [Editorial]. Health Sociol Rev 2009;18:3-11.

9. Ben-Shlomo Y, Kuh D. A life course approach to chronic disease epidemiology: conceptual models, empirical challenges and interdisciplinary perspectives. Int J Epidemiol 2002;31:285-93.

10. Halfon N, Hochstein M. Life course health development: an integrated framework for developing health, policy, and research. Milbank Q 2002;80:433-79, iii.

11. Graham H, Chris P. Childhood disadvantage and adult health: a lifecourse framework. London: NHS Health Development Agency, 2004. http://www.gserve.nice.org.uk/niceMedia/pdf/childhood_ disadvantage_health.pdf (accessed 24 May 2014).

12. Hertzman C, Power C, Matthews S, et al. Using an interactive framework of society and lifecourse to explain self-rated health in early adulthood. Soc Sci Med 2001;53:1575-85.

13. Mensah FK, Hobcraft J. Childhood deprivation, health and development: associations with adult health in the 1958 and 1970 British prospective birth cohort studies. J Epidemiol Community Health 2008;62:599-606.

14. Kestila L, Koskinen S, Martelin T, et al. Determinants of health in early adulthood: what is the role of parental education, childhood adversities and own education? Eur J Public Health 2006;16:305-14.

15. Pollitt R, Rose K, Kaufman J. Evaluating the evidence for models of life course socioeconomic factors and cardiovascular outcomes: a systematic review. BMC Public Health 2005;5:7.

16. Kelleher CC, Tay J, Gabhainn SN. Influence on self-rated health of socio-demographic, lifestyle and affluence factors: an analysis of the Irish and international health behaviours among school-aged children (HBSC) datasets 1998. Ir Med J 2007;100(8Suppl):43-6.

17. Stein RE, Siegel MJ, Bauman LJ. Double jeopardy: what social risk adds to biomedical risk in understanding child health and health care utilization. Acad Pediatr 2010;10:165-71.

18. Stevens GD. Gradients in the health status and developmental risks of young children: the combined influences of multiple social risk factors. Matern Child Health J 2006;10:187-99.

19. Krieger $\mathrm{N}$. Theories for social epidemiology in the 21 st century: an ecosocial perspective. Int J Epidemiol 2001;30:668-77.

20. Krieger N. A glossary for social epidemiology. J Epidemiol Community Health 2001;55:693-700.

21. Hertzman $\mathrm{C}$. The biological embedding of early experience and its effects on health in adulthood. Ann N Y Acad Sci 1999;896:85-95.

22. Hertzman C, Boyce T. How experience gets under the skin to create gradients in developmental health. Annu Rev Public Health 2010;31:329-47, C1-C3.

23. Butland B, Jebb S, Kopelman P, et al. Foresight. Tackling obesities: future choices-project report. London: Government Office for Science, 2007. http://www.bis.gov.uk/assets/foresight/docs/obesity/ 17.pdf (accessed 30 Mar 2012).

24. Aboderin I, Kalache A, Ben-Shlomo Y, et al. Life course perspectives on coronary heart disease, stroke and diabetes: key issues and implications for policy and research. Geneva: World Health Organization, 2002. http://whqlibdoc.who.int/hq/2002/WHO_ $\mathrm{NMH}$ NPH 02.1.pdf (accessed 30 Mar 2012).

25. Molarius A, Berglund K, Eriksson C, et al. Socioeconomic conditions, lifestyle factors, and self-rated health among men and women in Sweden. Eur J Public Health 2007;17:125-33.

26. Prosper M-H, Moczulski VL, Qureshi A. Obesity as a predictor of self-rated health. Am J Health Behav 2009;33:319-29.

27. Svedberg $\mathrm{P}$, Bardage C, Sandin S, et al. A prospective study of health, life-style and psychosocial predictors of self-rated health. Eur J Epidemiol 2006;21:767-76. 
28. Zajacova A, Burgard SA. Body weight and health from early to mid-adulthood: a longitudinal analysis. $J$ Health Soc Behav 2010;51:92-107.

29. Tsiros MD, Olds T, Buckley JD, et al. Health-related quality of life in obese children and adolescents. Int $J$ Obes (Lond) 2009;33:387-400.

30. Wake M, Hardy P, Sawyer MG, et al. Comorbidities of overweight/ obesity in Australian preschoolers: a cross-sectional population study. Arch Dis Child 2008;93:502-7.

31. Skinner AC, Perrin EM, Steiner MJ. Healthy for now? A cross-sectional study of the comorbidities in obese preschool children in the United States. Clin Pediatr (Phila) 2010;49:648-55.

32. O'Mahony D, Fallon UB, Hannon F, et al. The Lifeways Cross-Generation Study: design, recruitment and data management considerations. Ir Med J 2007;100(8Suppl):3-6.

33. Niedhammer I, O'Mahony D, Daly S, et al. Occupational predictors of pregnancy outcomes in Irish working women in the Lifeways cohort. BJOG 2009;116:943-52.

34. Murrin CM, Kelly GE, Tremblay RE, et al. Body mass index and height over three generations: evidence from the Lifeways Cross-Generational Cohort Study. BMC Public Health 2012;12:81.

35. National Nutrition Surveillance Centre. Dietary habits of the Irish population: results from SLÁN, annual report 2003. Dublin: National Nutritional Surveillance Centre, Department of Public Health Medicine and Epidemiology, University College Dublin, Dublin and Health Promotion Unit, Department of Health and Children, Dublin, 2003.

36. Murrin C. Maternal factors during pregnancy contributing to early life risk of childhood obesity [PhD Thesis]. Dublin: University College Dublin, 2011

37. Harrington J. Validation of a food frequency questionnaire as a tool for assessing nutrient intake [MA Thesis]. Galway: National University of Ireland, 1997.

38. Gregory J, Collins D, Davies P, et al. National Diet and Nutrition Survey: children aged 1.5-4.5 years. Volume 1: Report of the diet and nutrition survey. London: HMSO, 1995.

39. Food Standards Agency. McCance and Widdowson's the composition of foods, sixth summary edition. Cambridge: Royal Society of Chemistry, 2002.

40. FFQ Software version 1.0. Dublin: National Nutrition Surveillance Centre, School of Public Health and Population Science, University College Dublin, 2007.

41. Monette S, Séguin L, Gauvin L, et al. Validation of a measure of maternal perception of the child's health status. Child Care Health Dev 2007:33:472-81.

42. Katz MH. Multivariable analysis: a practical guide for clinicians and public health researchers. 3rd edn. New York: Cambridge University Press, 2011.

43. Rogers I; the EURO-BLCS Study Group. The influence of birthweight and intrauterine environment on adiposity and fat distribution in later life. Int $J$ Obes Relat Metab Disord 2003;27:755-77.

44. Wells JC, Chomtho S, Fewtrell MS. Programming of body composition by early growth and nutrition. Proc Nutr Soc 2007;66:423-34.

45. Wake M, Salmon L, Waters E, et al. Parent-reported health status of overweight and obese Australian primary school children: a cross-sectional population survey. Int J Obes Relat Metab Disord 2002;26:717-24

46. Swallen KC, Reither EN, Haas SA, et al. Overweight, obesity, and health-related quality of life among adolescents: the National Longitudinal Study of Adolescent Health. Pediatrics 2005;115:340-7.

47. Vingilis ER, Wade TJ, Seeley JS. Predictors of adolescent self-rated health. Analysis of the National Population Health Survey. Can J Public Health 2002;93:193-7.

48. Kelleher CC, Whelan J, Daly L, et al. Socio-demographic, environmental, lifestyle and psychosocial factors predict self rated health in Irish Travellers, a minority nomadic population. Health Place 2012;18:330-8.

49. Kelleher CC, Friel S, Nic Gabhainn S, et al. Socio-demographic predictors of self-rated health in the Republic of Ireland: findings from the National Survey on Lifestyle, Attitudes and Nutrition, SLAN. Soc Sci Med 2003;57:477-86.

50. Eiser C, Morse R. Can parents rate their child's health-related quality of life? Results of a systematic review. Qual Life Res 2001;10:347-57.

51. Upton P, Lawford J, Eiser C. Parent-child agreement across child health-related quality of life instruments: a review of the literature. Qual Life Res 2008;17:895-913.

52. Norrby U, Nordholm L, Fasth A. Reliability and validity of the Swedish version of child health questionnaire. Scand J Rheumatol 2003;32:101-7.
53. Davis E, Nicolas C, Waters E, et al. Parent-proxy and child self-reported health-related quality of life: using qualitative methods to explain the discordance. Qual Life Res 2007;16:863-71.

54. Theunissen NC, Vogels TG, Koopman HM, et al. The proxy problem: child report versus parent report in health-related quality of life research. Qual Life Res 1998:7:387-97.

55. Varni JW, Limbers CA, Burwinkle TM. Parent proxy-report of their children's health-related quality of life: an analysis of 13,878 parents reliability and validity across age subgroups using the PedsQL 4.0 Generic Core Scales. Health Qual Life Outcomes 2007;5:2.

56. Spencer NJ, Coe C. The development and validation of a measure of parent-reported child health and morbidity: the Warwick Child Health and Morbidity Profile. Child Care Health Dev 1996;22:367-79.

57. Spencer NJ, Coe C. Validation of the Warwick Child Health and Morbidity Profile in routine child health surveillance. Child Care Health Dev 2000;26:323-36.

58. McCormick MC, Brooks-Gunn J, Workman-Daniels K, et al. Maternal rating of child health at school age: does the vulnerable child syndrome persist ? Pediatrics 1993;92:380-8.

59. McCormick MC, Brooks-Gunn J, Shorter T, et al. Factors associated with maternal rating of infant health in central Harlem. J Dev Behav Pediatr 1989;10:139-44.

60. McCormick MC, Athreya BH, Bernbaum JC, et al. Preliminary observations on maternal rating of health of children: data from three subspecialty clinics. J Clin Epidemiol 1988;41:323-9.

61. Lynch JL. Infant health, race/ethnicity, and early educational outcomes using the ECLS-B. Sociol Inq 2011;81:499-526.

62. Gilman SE, McCormick MC. Insights from life course epidemiology. Acad Pediatr 2010;10:159-60.

63. Smith KW, Avis NE, Assmann SF. Distinguishing between quality of life and health status in quality of life research: a meta-analysis. Qual Life Res 1999;8:447-59.

64. Pinhas-Hamiel O, Singer S, Pilpel N, et al. Health-related quality of life among children and adolescents: associations with obesity. Int $J$ Obes (Lond) 2006;30:267-72.

65. Williams J, Wake M, Hesketh $\mathrm{K}$, et al. Health-related quality of life of overweight and obese children. JAMA 2005;293:70-6.

66. de Beer M, Hofsteenge GH, Koot HM, et al. Health-related-qualityof-life in obese adolescents is decreased and inversely related to BMI. Acta Paediatr 2007:96:710-14.

67. Shibli R, Rubin L, Akons $\mathrm{H}$, et al. Morbidity of overweight ( $\geq 85$ th percentile) in the first 2 years of life. Pediatrics 2008;122:267-72.

68. Suglia SF, Chambers EC, Rosario A, et al. Asthma and obesity in three-year-old urban children: role of sex and home environment. $J$ Pediatr 2011;159:14-20.e11.

69. Tai A, Volkmer R, Burton A. Association between asthma symptoms and obesity in preschool (4-5 year old) children. $J$ Asthma 2009;46:362-5.

70. Slining M, Adair LS, Goldman BD, et al. Infant overweight is associated with delayed motor development. J Pediatr 2010;157:20-5.e21.

71. Williams JW, Canterford L, Hesketh KD, et al. Changes in body mass index and health related quality of life from childhood to adolescence. Int J Pediatr Obes 2011;6:e442-8.

72. Marmot M, Friel S, Bell R, et al. Closing the gap in a generation: health equity through action on the social determinants of health. Lancet 2008;372:1661-9.

73. Imai K, Gregg EW, Chen YJ, et al. The association of BMI with functional status and self-rated health in US adults. Obesity (Silver Spring) 2008;16:402-8.

74. Simonsen MK, Hundrup YA, Grønbaek M, et al. A prospective study of the association between weight changes and self-rated health. BMC Womens Health 2008;8:13.

75. Cameron AJ, Magliano DJ, Dunstan DW, et al. A bi-directional relationship between obesity and health-related quality of life: evidence from the longitudinal AusDiab study. Int $J$ Obes (Lond) 2012;36:295-303.

76. Sawyer MG, Harchak T, Wake M, et al. Four-year prospective study of $\mathrm{BMI}$ and mental health problems in young children. Pediatrics 2011;128:677-84.

77. Jansen PW, Mensah FK, Clifford S, et al. Bidirectional associations between overweight and health-related quality of life from 4-11 years: Longitudinal Study of Australian Children. Int J Obes (Lond) 2013;37:1307-13.

78. Coneus K, Spiess CK. The intergenerational transmission of health in early childhood-evidence from the German Socio-Economic Panel Study. Econ Hum Biol 2012;10:89-97.

79. Case A, Lubotsky D, Paxson C. Economic status and health in childhood: the origins of the gradient. Am Econ Rev 2002;92:1308-34. 
80. Silburn SR, Zubrick SR, Garton A, et al. Western Australia Child Health Survey: family and community health. Perth, Western Australia: Australian Bureau of Statistics and the TVW Telethon Institute for Child Health Research, 1996.

81. Waters E, Doyle J, Wolfe R, et al. Influence of parental gender and self-reported health and illness on parent-reported child health. Pediatrics 2000;106:1422-8.

82. Dadds MR, Stein RE, Silver EJ. The role of maternal psychological adjustment in the measurement of children's functional status. $J$ Pediatr Psychol 1995;20:527-44.

83. Boyd A, Golding J, Macleod J, et al. Cohort profile: the 'children of the 90s'-the index offspring of the Avon Longitudinal Study of Parents and Children. Int J Epidemiol 2013;42:111-27.
84. Fraser A, Macdonald-Wallis C, Tilling $\mathrm{K}$, et al. Cohort profile: the Avon Longitudinal Study of Parents and Children: ALSPAC mothers cohort. Int J Epidemiol 2013; 42:97-110.

85. Howe L, Galobardes B, Tilling K, et al. Does drop-out from cohort studies bias estimates of socioeconomic inequalities in health? J Epidemiol Community Health 2011;65:A31.

86. Wolke D, Waylen A, Samara M, et al. Selective drop-out in longitudinal studies and non-biased prediction of behaviour disorders. Br J Psychiatry 2009;195:249-56.

87. Nilsen RM, Vollset SE, Gjessing HK, et al. Self-selection and bias in a large prospective pregnancy cohort in Norway. Paediatr Perinat Epidemiol 2009;23:597-608. 